\title{
"I wrote as if I were telling a story to someone I knew.": Designing Chatbot Interactions for Expressive Writing in Mental Health
}

\author{
SoHyun Park \\ Seoul National University, Seoul, \\ Korea \\ sohyun@snu.ac.kr \\ Sungwoo Lee \\ Seoul National University, Seoul, \\ Korea \\ lsw0504@snu.ac.kr
}

\author{
Anja Thieme \\ Microsoft Research, Cambridge, \\ United Kingdom \\ anthie@microsoft.com \\ Wonjong Rhee \\ Seoul National University, Seoul, \\ Korea \\ wrhee@snu.ac.kr
}

\author{
Jeongyun Han \\ Seoul National University, Seoul, \\ Korea \\ hanjy@snu.ac.kr \\ Bongwon Suh \\ Seoul National University, Seoul, \\ Korea \\ bongwon@snu.ac.kr
}

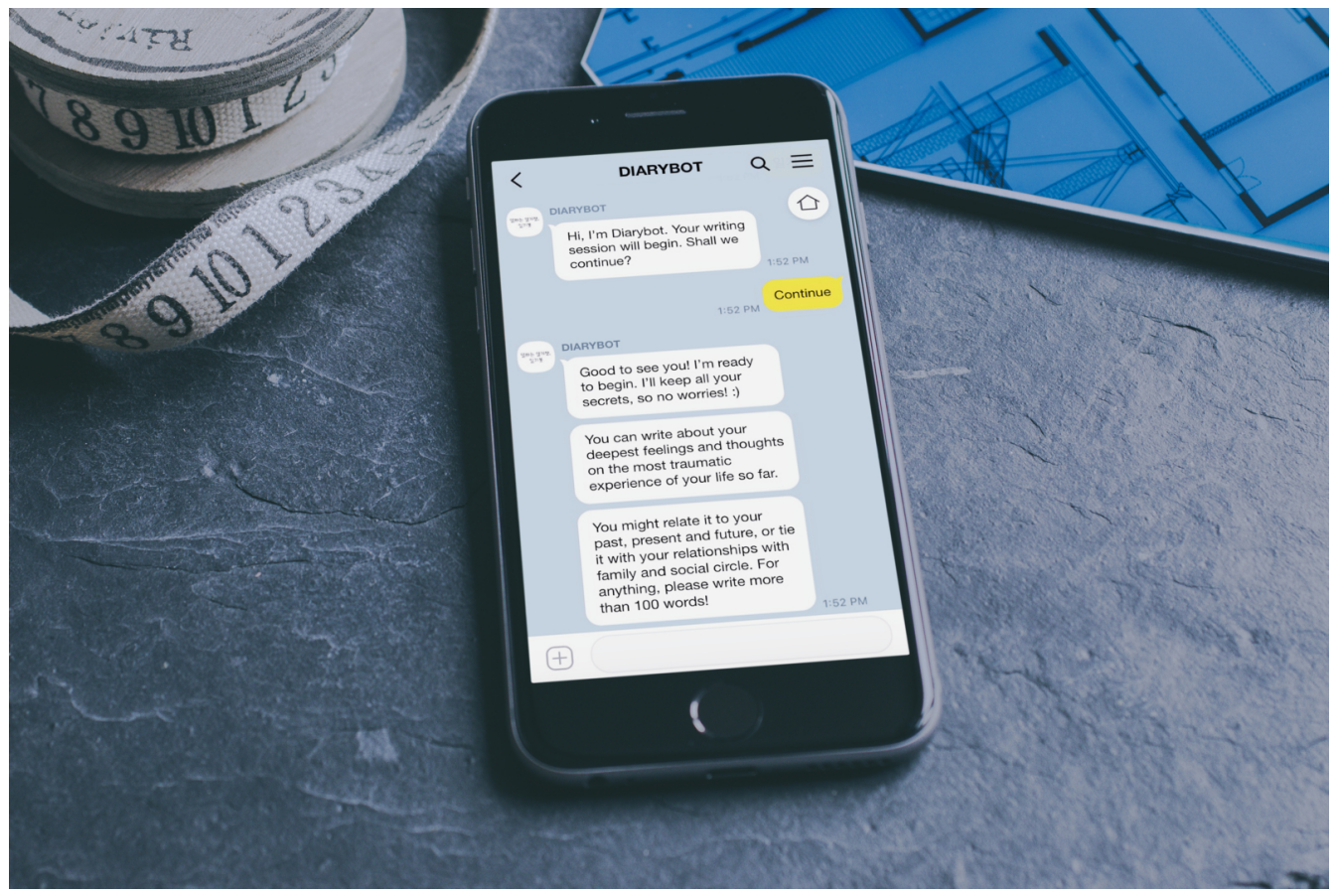

Figure 1: We designed a chatbot assistant for expressive writing called Diarybot. Users can access the bot on a mobile or PC messenger app.

\begin{abstract}
Writing about experiences of trauma and other challenges in life is known to provide measurable health benefits. Though writing for an audience may ensure better benefits, confiding one's most troubled memories in others risks a social stigma. Conversational

Permission to make digital or hard copies of all or part of this work for personal or classroom use is granted without fee provided that copies are not made or distributed for profit or commercial advantage and that copies bear this notice and the full citation on the first page. Copyrights for components of this work owned by others than ACM must be honored. Abstracting with credit is permitted. To copy otherwise, or republish, to post on servers or to redistribute to lists, requires prior specific permission and/or a fee. Request permissions from permissions@acm.org.

DIS '21, fune 28- July 02, 2021, Virtual Event, USA

(C) 2021 Association for Computing Machinery.

ACM ISBN 978-1-4503-8476-6/21/06...\$15.00

https://doi.org/10.1145/3461778.3462143
\end{abstract}

agents can provide a virtual audience that ensures privacy and allows social disclosure. To understand the writing experience with an agent, we created Diarybot, a chatbot assistant for expressive writing. We designed two versions, Basic and Responsive, to explore the writing experience with and without bot follow-up interactions compared to a Google doc baseline. Findings from a 4-day user study with 30 participants reveal that social disclosure with Diarybot can encourage narrative writing, with relative ease and emotional expression in Basic chat. Responsive chat can mediate social acceptance of the bot and provide guidance for self-reflection in the process. We discuss design reflections on social disclosure with agents in pursuit of wellbeing. 


\section{CCS CONCEPTS}

- Human-centered computing $\rightarrow$ Human computer interaction (HCI); Interaction paradigms; Natural language interfaces.

\section{KEYWORDS}

Expressive writing, chatbots, mental health, user experience

\section{ACM Reference Format:}

SoHyun Park, Anja Thieme, Jeongyun Han, Sungwoo Lee, Wonjong Rhee, and Bongwon Suh. 2021. "I wrote as if I were telling a story to someone I knew.": Designing Chatbot Interactions for Expressive Writing in Mental Health. In Designing Interactive Systems Conference 2021 (DIS '21), June 28-fuly 02, 2021, Virtual Event, USA. ACM, New York, NY, USA, 16 pages. https://doi.org/10.1145/3461778.3462143

\section{INTRODUCTION}

For decades, it has been established in psychology that expressive writing about a trauma can improve both physical and mental health [6, 49]. People who engage in this practice write about a traumatic event for 15-20 minutes for about 3-5 days [65]. Previous research that showed beneficial outcomes of expressive writing $[51,74,94]$ describes better immune function and mood [27, 68], and reduced physician visits [10]. Also, the simplicity of its format has made it an effective instrument to be used in conjunction with other clinical interventions [26, 51, 61, 80,94].

Because expressive writing is usually self-administered, it relies heavily on the person to keep involved in the task [34]. Yet previous research has pointed out that involving others in the experience of self-disclosure could have even broader benefits [72]. Self-disclosure in a social setting, however, carries risks of vulnerability and information loss because disclosers have to give up, to certain extent, privacy and personal control, over how their personal information may be further shared and engaged with [1, 92]. Furthermore, one may fear that sharing a troubled memory may cause social inference that may harm a person's reputation [23].

This suggests that conversational agents may present as a safer and more robust strategy to complement expressive writing. Kim et al. [41] reports how teenagers were happy talking to an agent about their personal problems, perceiving the agent as good listener, who is free of judgement and keeps any secrets separate from the human world. In addition, it is suggested in HCI that people engage with conversational agents in a way that they would in naturally occurring social interactions with other people [57]. This suggests that conversational agents may be well suited to act as a virtual audience for writers to engage in a social sharing of negative emotions, rather than musing on it alone.

Furthermore, if designed correctly, conversational agents can offer interactions that can better guide the user through their thought process and assist their narrative to avoid ruminative or brooding thought, a counter factor that is often discussed in expressive writing $[21,29,67,86]$. Though there have been attempts to introduce more structure to the writing $[29,47]$, to encourage non-ruminative narratives, imposing too much specificity in the writing instructions may restrain the way in which people would naturally express themselves, and could hinder their willingness to work through the activity [60]. Conversational agents can naturally engage the user in an interaction that can help write in a stepwise, procedural manner.

We designed Diarybot, a chatbot that assists expressive writing (Figure 1). To understand the writing experience with the chatbot, we created two versions. Basic chat simply replicates the structure of expressive writing as informed by the literature in a chat format. Responsive chat extends Basic chat, by providing situated prompts in response to any feelings the person expressed in the writing and persons mentioned. With this variation, we study the effectiveness of designing chatbot interactions to deliver expressive writing for its intended benefits and to explore further elaborations of the practice.

To compare user experience with Diarybot to a baseline, we set up a Google document that includes the same writing instructions, but no chat functionality. We conducted a user study with 30 participants, who were randomly assigned to one of the three conditions: baseline, Basic chat, and Responsive chat. Each participant signed up for four consecutive days of a week to write about some of their most difficult experiences in life. Our findings reveal that both Diarybots could mediate social sharing of emotions, where participants could engage in telling their stories. Expressive writing was significantly less difficult and more conducive for emotional expression in Basic chat, compared to the baseline. Increased interactivity in Responsive chat led to perceived social acceptance of the bot, and situated prompts offered a chance for self-reflection and to get thoughts in order. Based on the findings, we discuss designing chatbot interactions for expressive writing in pursuit of emotional wellbeing.

To the best of our knowledge, this work is one of the first attempts to make expressive writing interactive with a chatbot. We contribute: (1) the design and implementation of a chat-based, interactive assistant for expressive writing; (2) empirical findings from a user study that chatbots can encourage social disclosure, and the chat design can shape the narrative experience differently; and (3) design reflections on conversational agents for self-disclosure and wellbeing.

\section{BACKGROUND AND HYPOTHESES}

We review previous research on written self-disclosure, social sharing of emotions, and chat interaction design.

\subsection{Written Self-Disclosure}

The term "self-narrative" in narrative psychology refers to the type of stories that we construct to make sense of critical life events [22]. For decades, Pennebaker et al. have studied this act of constructing a story on traumatic life experiences that lead to improved health outcomes [6, 64-66, 68, 71, 85]. Widely referred to as "expressive writing," they have used the following writing instructions [68]:

For the next four days, I would like for you to write about your very deepest thoughts and feelings about the most traumatic experience of your entire life. In your writing, I'd like you to really let go and explore your very deepest emotions and thoughts. You might tie your topic to your relationships with others, including parents, lovers, friends, or relatives, to your past, your present, or your future, or to who you have been, who 
"I wrote as if I were telling a story to someone I knew.": Designing Chatbot Interactions for Expressive Writing in Mental Health

you would like to be, or who you are now. You may write about the same general issues or experiences on all days of writing or on different traumas each day. All of your writing will be completely confidential.

Pennebaker and colleagues found that writing on traumas for as short as 15 minutes for 3 to 5 days turned out to be a significantly meaningful experience for the vast majority of participants in their studies; and to cause health benefits, including reduced physician visits and improved immune function [68,71]. In fact, expressive writing has been widely studied as an important therapeutic instrument $[13,25,26,46,83,84]$. However, it can be difficult for a writer, similar as it often is for patients undergoing psychotherapeutic interventions, to construct a coherent story and understand the past and present life concerns [17, 68]. While the use of insightful words (e.g. understand, realize, see) and words that suggest causal relationships (e.g. because, why) has been reported in correlation with health benefits $[14,69,87]$, some studies report that individuals who wrote in such manner still did not benefit from the writing [67, 68].

It is best thought that the process of forming a coherent narrative leads to salutary effects $[14,40,58]$. A number of modifications and adaptations have been studied in the writing procedure and methods [71]. Some made Pennebaker's original instructions more specific, i.e. instructing participants to write in a structured manner (e.g. [29, 80, 85]). However, critique points out that such approach deviates from the "expressive" nature of the writing paradigm [21] Once writing is instructed to be done in a specific manner, it loses the point to let go of all feelings and thoughts as originally intended.

Instead, the ecological setting of the writing has been taken into consideration. Originally a non-social procedure, expressive writing is carried out, or encouraged to do so, by a writer alone $[69,70]$. Though the writer may be unattended in the process, it is required that for research purposes the writing is submitted to the researcher at the end. In Radcliffe et al. [72], the effect of submission is tested for social effect as shared writing, as opposed to private writing, i.e. the writing is kept by, and only accessible to, the writer. Their results show shared writing reduced depression, interpersonal sensitivity and physical symptoms, a potential for broader benefits than private writing.

In this work, we are motivated to use a text-based conversational agent, a chatbot, to design a social procedure for expressive writing. To explore its impact, we are keen to find how it may influence the writing process. We hypothesize:

H1. Expressive writing in a social setting will include more social language than that in a non-social condition.

To further investigate the sociality of the process, we now review the social sharing of emotions to study discloser motivations and experiences.

\subsection{Social Sharing of Emotions}

Previous research has that we are wired to share our emotions with others [11, 59, 75, 77]. More often than not, emotional experiences are shared shortly after they occur [76]. When expectations fail and goals fall through, we seek reasons to account for our failures [75]. An intrapersonal search for meaning and effort to resolve rumination alone cannot exhaust all emotional consequences [75].
An earlier work [79] suggests that individuals in distress engage with others who share the same fate to evaluate their own emotions. These interactions occur in the forms of social comparison, conversation, narration, storytelling, often pursuing emotional support [75].

However, people also have conflicting motives in deciding to share their feelings and may refrain from it after all. Feelings associated with one's unfortune events often accompany fear, vulnerability, and embarrassment if exposed to public [1]. For instance, Yang et al. [92] has discovered that privacy matters in sharing health concerns online. Members of cancer support groups had greater motivations to self-disclose their illness concerns in private channels than in public channels. They found that peer self-disclosure was also greater in private channels as well. Likewise, Rains [73] shows that among 114 health bloggers, illness-related embarrassment was positively associated with anonymity as well as self-disclosure. This means that while negative emotions motivate people to share, people also want to keep them private to save face and avoid social stigma.

Conversational agents can be a solution. Commonly referred to as the phrase "computers are social actors (CASA)," it is widely accepted in $\mathrm{HCI}$ that people sometimes interact with the computer in ways that mimic social interactions with others, especially when it has certain anthropomorphic qualities [44,57]. Evidence has that social disclosure with a chatbot is comparable to that with humans [33], and that even deeper disclosure is possible with computers [48]. In fact, conversational agents, e.g. text-based and embodied agents, are now introduced in mental healthcare. So-called "chatbot therapists," e.g. Woebot [20], Wysa [37], are in popular and successful service. Once users engage, they walk them through a series of exercises such as cognitive reframing, etc., in an Internetfriendly language. In studies with depressed individuals, they have shown their effectiveness compared to a non-agent control condition [20,37]. Others include virtual humans [48] and relational agents $[3,4,81,88]$, with evidence for less fear of self-disclosure and more intense emotional expression in interacting with agents, and that such interaction is enjoyable and capable of facilitating empathy and trust with these agents, leading to positive health behavior.

Taken together, we find chatbots a suitable candidate to design expressive writing interaction for social disclosure. We construct a two-part hypothesis that:

H2-(a). Users will find expressive writing with a chatbot more engaging than writing without it.

H2-(b). Users will perceive a chatbot as a socially acceptable companion in expressive writing.

As conversation the primary medium of interaction, how chatbots generate a conversation matters in user perceptions of sociability as well as in wellbeing. In the following, we study what the interaction should aim at for emotional recovery, and the design of prior chat interventions.

\subsection{Conversation Design for Mental Health}

In emotions research, it is studied that sharing emotions can take either the socio-affective route or the cognitive route [75]. According to Rimé [75], most take the socio-affective route, where people 
readily engage in interactions with others to seek consolation and support. This process helps to release negative emotions and feel secure from the emotional threat that is causing the distress. On the other hand, the cognitive route involves articulating and reaccommodating the once-lost motives and goals, seeking cognitive reasoning behind the distress. This is a process that may not naturally arise in response to distress; however, research has shown that it is the cognitive route that actually leads to recovery $[75,76]$, as the emotional support earned from social gatherings are often fleeting and therefore tend to be repeated in a loop.

Findings from Rimé's work suggest that to achieve emotional recovery, the social setting of sharing emotions should encourage one to learn lessons and find meaning. This aligns with the cognitiveconstructivist thought in psychotherapy [89] where the therapist recognizes the patient's emotional experience and tries to interpret it, i.e. a cognitive reappraisal process. In cognitive-behavior therapy (CBT), interpretation takes place when a client evaluates psychological threat [8] and the therapist tries to help restructure any maladaptive thoughts [36]. In the context of a chatbot interaction for expressive writing, the interaction should therefore be designed not only to encourage the release of negative thoughts and feelings but also to help cognitive processing of an emotional experience.

Since expressive writing in its original format does not involve any social interaction, we plan to create an additional version of chatbot that offers further chat interactions as a follow-up to the writing. To design the follow-up, we look at how conversations are designed in computerized interventions for mental health. We find many examples that focus on the technical implementation of the chat generation (e.g. [16]), how human dialogue compares to machine's (e.g. [53]), or best practices for incorporating the chatbot technology (e.g. [9, 54]). Here, we focus on the methodological discussion on how the chat is designed. For example, SimSensei Kiosk [15], a virtual interviewer that assesses distress state for individuals with PTSD and anxiety, leads a speech-based conversation with four natural language understanding (NLU) classifiers to identify the dialogue act, valence, and small talk. In response, the agent is programmed to retrieve an appropriate response from a pool of 100 pre-installed utterances. This find-and-match algorithm is useful to preserve conversational context and continue on with the conversation [90].

More relevant to our work include the automated feedback system for expressive writing [6] and peer-to-peer chat [62]. In Bond and Pennebaker [6], a computer-generated feedback is provided on a writer's pronoun use, to effectively mediate the writer's perspective switching in multiple expressive writing sessions. At each round, a simple feedback on how much self-related pronouns were used compared to other-related ones is provided, asking to make adequate changes in the subsequent round to adjust their focus. The directive intervention worked in changing how participants wrote, although their health or subjective benefits remained unchanged.

For more fluid back-and-forth interaction, chat can be designed with a sequence of aims and skills. In O'Leary et al. [62] two types of peer support chats are designed, guided and unguided. Largely following a mock psychotherapy session, the guided chat instructs the user to follow specific therapeutic skills in conversation, while the unguided chat the user is free to engage with the other. Study

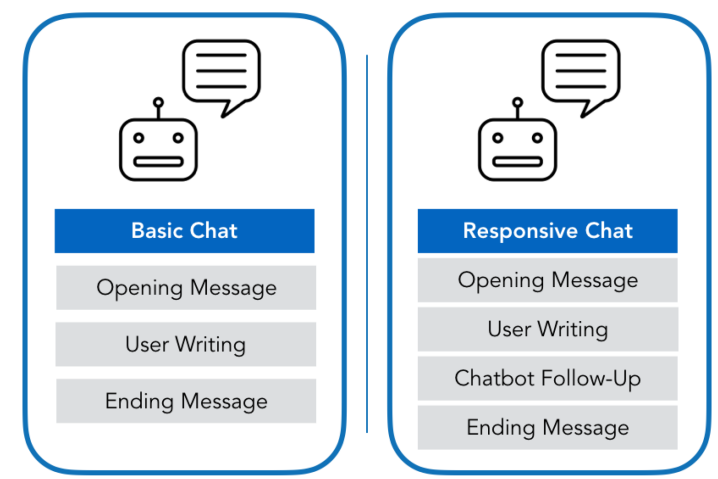

Figure 2: Chat interactions for Basic chat and Responsive chat. Responsive chat adds a follow-up with situated prompts.

participants found the unguided chat more cathartic and enjoyable, and the guided chat offering new perspectives and deeper insights. Similarly, in Park et al. [63], a chatbot motivational interview is designed with motivational interviewing micro-skills, where participants reported the benefit of self-reflection.

We find that these studies speak to the potential of sequenced bot utterances trained on therapist skills to follow up with expressive writers. The aim of the follow up is to encourage writers to review a past trauma and make better interpretations. Our final hypothesis is as follows:

H3. Writing with the bot follow-up interactions will help writers interpret better than writing without follow-up.

Based on the literature review, we detail our design and implementation of the bot in the following section.

\section{DIARYBOT}

We built Diarybot on one of the most popular messenger apps used in Korea, KakaoTalk ${ }^{1}$, on which a user can add a chatbot in the same way that they would add a friend. We customized two different sets of the bot "skills," a set of programmed scripts to design Diarybot's Basic chat and Responsive chat (Figure 2). Though the bot was implemented in Korean, all figures and examples are translated in English for the purposes of this paper.

\subsection{Basic Chat}

The aim of the Basic chat is to deliver the expressive writing instructions by Pennebaker et al. [68] (described above) on a chatbot interface, translated into more casual, conversational language. It goes: "[Good to see you! I'm ready to begin. I'll keep all your secrets, so no worries. :)] [You can write about your deepest feelings and thoughts on the most traumatic experience of your life so far.] [You might relate it to your past, present and future, or tie it with your relationships with family and social circle. For anything, please write more than 100 words!]" Brackets indicate chat bubbles, as we broke down the instructions for better readership. At completion of the writing, the bot says "Thank you for writing today. Your session is finished. See

\footnotetext{
${ }^{1}$ https://www.kakaocorp.com/service/KakaoTalk?lang=en

${ }^{2}$ https://i.kakao.com/login
} 
"I wrote as if I were telling a story to someone I knew.": Designing Chatbot Interactions for Expressive Writing in Mental Health

DIS '21, June 28-July 02, 2021, Virtual Event, USA

Table 1: An example conversation in Basic chat with Diarybot. All user responses are made up for demonstration purposes.

\begin{tabular}{ll}
\hline \multicolumn{1}{c}{ Speaker } & \multicolumn{1}{c}{ Response } \\
\hline Diarybot & Hi, I'm Diarybot. Your writing session will begin. Shall we continue? \\
[buttons to select: 'Later' or 'Continue'] \\
User & [button selected] Continue \\
Diarybot & Good to see you! I'm ready to begin. I'll keep all your secrets, so no worries. :) \\
& You might relate it to your past, present and future, or tie it with your relationships with family and social circle. For \\
& anything, please write more than 100 words! \\
User & I utterly hated it. I tried to say no many times, but my mum took it as a joke and lured me with toys or told me to \\
& toughen up. Growing up, I never told mum how I felt back then. I guess mum must have forgotten all about it. I \\
& hardly recall the specifics of the times, either. But whenever the memory surfaces, a feeling of distant fear makes \\
& me shiver. I don't know if it is the water, or the fear itself, or my mum. \\
& Thank you for writing today. Your session is finished. See you again soon! \\
\hline
\end{tabular}

Table 2: Situated prompts in Responsive chat. Diarybot fills all alphabet placeholders with keywords from user writing.

\begin{tabular}{ll}
\hline \multicolumn{1}{c}{ Target Awareness } & \multicolumn{1}{c}{ Example Prompt } \\
\hline Emotional & - In your writing today, feelings such as A, B, C, D are found. What impact have they had on your body and \\
& mind? \\
Social/Situational & - Now let's think about X. What have you received from X, if anything? \\
& - Then what have you given to X? Even tiniest things are welcome. \\
& - Four time. \\
Self & - Before we wrap up our writing today, what would you like to say to yourself? \\
\hline
\end{tabular}

you again soon?' We provide an example of the Basic chat in Table 1.

\subsection{Responsive Chat}

The Responsive chat uses the same chat sequence; however, it follows up on the user's writing with 5 situated open-ended question prompts. The questions were designed to help a user review what he or she has written in response to the initial instructions; they are based on a combination of three therapeutic techniques that can help the user reflect on past feelings, social relationships or situational circumstances, and his or her self (Table 2). We explain the rationale for choosing these questions.

Emotional awareness. In psychotherapy, feelings need to be recognized before any interpretive action to be taken [89]. To invite users to reflect specifically on their feelings and how they impact them, Diarybot retrieves all negative sentiments that are detected in the writing via an API-serviced deep learning algorithm ${ }^{3}$, and ranks them in order of intensity. Up to 4 highly intense emotions are extracted to be incorporated in the prompt. If no sentiment is identified, the user is asked to describe "how they feel at the moment", a more general question.

Social/Situational awareness. Three questions from the Naikan therapy are used to promote the writer's social awareness.

\footnotetext{
${ }^{3}$ https://www.adams.ai/
}

Naikan is a Japanese meditation practice that centers on three questions to help reflect on the feelings an individual may have about a person, a thing, or any subject in particular, marked with an $\mathrm{X}$ below [82].

- What have you received from X, if anything?

- What have you given to X?

- What troubles, if any, have you caused X?

In Responsive chat, $\mathrm{X}$ is replaced with a person that the user mentions in the writing. To obtain such person information, TextRank algorithm $[39,52]$ is applied to extract keywords of the writing and match them against a set of familial (e.g. Mom, Dad), social (e.g. Friend), and occupational (e.g. Teacher, Professor) words in the text, retrieved by an API that services predefined lists of categories and dictionaries ${ }^{4}$. If Diarybot does not identify a match, it defaults to templated questions that asks the user to re-evaluate the actions that they had taken, could not have, and would like to have taken (Figure 3), to promote situational awareness.

Self-awareness. Finally, Diarybot asks the writers to leave a message for themselves. This is intended to invoke a summarization of the entire interaction so as to facilitate a re-construction of any meaning from the writing [24], and present a natural conclusion to

\footnotetext{
${ }^{4}$ http://aiopen.etri.re.kr/
} 
Table 3: An example conversation in Responsive chat with Diarybot. All user responses are made up for demonstration purposes.

\begin{tabular}{|c|c|}
\hline Speaker & Response \\
\hline Diarybot & $\begin{array}{l}\text { Hi, I'm Diarybot. Your writing session will begin. Shall we continue? } \\
\text { [buttons to select: 'Later' or 'Continue'] }\end{array}$ \\
\hline User & [button selected] Continue \\
\hline \multirow[t]{2}{*}{ Diarybot } & Good to see you! I'm ready to begin. I'll keep all your secrets, so no worries. :) \\
\hline & $\begin{array}{l}\text { You can write about your deepest feelings and thoughts on the most traumatic experience of your life so far. } \\
\text { You might relate it to your past, present and future, or tie it with your relationships with family and social circle. For } \\
\text { anything, please write more than } 100 \text { words! }\end{array}$ \\
\hline User & $\begin{array}{l}\text { When I was little, I was terrified of water. Mum always tried to take me to the pool to teach me how to swim, but } \\
\text { I utterly hated it. I tried to say no many times, but my mum took it as a joke and lured me with toys or told me to } \\
\text { toughen up. Growing up, I never told mum how I felt back then. I guess mum must have forgotten all about it. I } \\
\text { hardly recall the specifics of the times, either. But whenever the memory surfaces, a feeling of distant fear makes } \\
\text { me shiver. I don't know if it is the water, or the fear itself, or my mum. }\end{array}$ \\
\hline Diarybot & $\begin{array}{l}\text { In your writing today, feelings of "terrified," "hate," and "fear" were found. What impact have they had on your body } \\
\text { and mind? }\end{array}$ \\
\hline User & I feel weak, as in I feel slightly under the weather? I feel insecure. \\
\hline Diarybot & $\begin{array}{l}\text { Now let's think more about "mum" in your writing. What have you received from your relationship with mum, if } \\
\text { anything? }\end{array}$ \\
\hline User & $\begin{array}{l}\text { Well, she's done a lot of things for me. She has been a supportive, dedicated mother, though there were times that } \\
\text { her philosophies didn't really click with me. }\end{array}$ \\
\hline Diarybot & What about the things you tried for mum? You can write the things you've done so far. \\
\hline User & I was a good child, for sure. I tried to fulfill all of her wishes for me all along. \\
\hline Diarybot & $\begin{array}{l}\text { Let's move on. What difficulties or trouble have you caused in your relationship with mum? Take your time and think } \\
\text { about it. }\end{array}$ \\
\hline User & $\begin{array}{l}\text { Erm... I know she made many sacrifices for me. We were never that well-to do, for sure. There were times that I } \\
\text { snapped and yelled at her especially in high school years. }\end{array}$ \\
\hline Diarybot & I hope you muse on these things a while. Before we wrap up our writing today, what would you like to say to yourself? \\
\hline User & I guess it may not be as bad as I thought it to be, but I think I will have to work on my feelings for a while first. \\
\hline Diarybot & Thank you for writing today. Your session is finished. See you again soon! \\
\hline
\end{tabular}

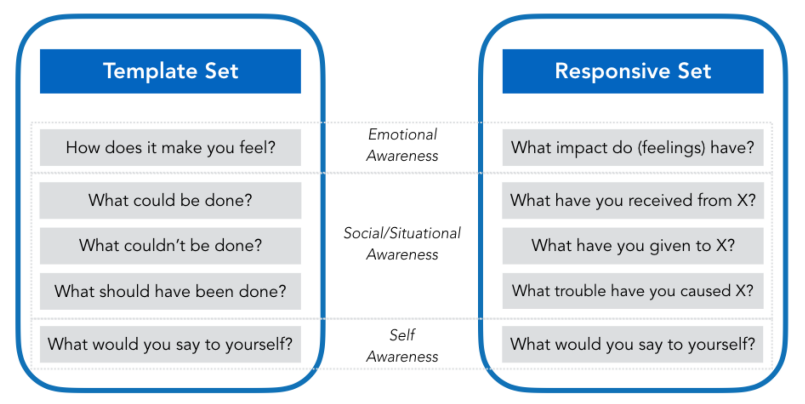

Figure 3: Prompts in Responsive chat. Template set of prompts are asked if Diarybot finds no keywords.

the activity. A complete example of Responsive chat is provided in Table 3.

To ensure smooth proceeding of the bot follow-up, a series of pilot study was conducted. Modifications were made in the questions to better communicate their purpose. We tried different number of prompts, especially for emotional and self-awareness; however, we settled on the five prompts to allow just enough nudge for reflective thinking and to refrain from bombarding questions. Also, to maintain consistency yet to avoid too much redundancy in the 4-day study deployment, we reproduced 5 sets of all prompts with synonymous phrases. Finally, for the bot's skills to work properly, users had to write at least 100 words to proceed. To ensure this, we instructed baseline participants to use the word count function.

Finally, we set up a baseline writing medium in a Google document, an online text editor where content is sharable. To keep the writing instructions as consistent as possible, we provided the same instructions except for the greetings in Diarybot conditions: "Here, you can write about your deepest feelings and thoughts on the most traumatic experience of your life so far. You might relate it to your past, present and future, or tie it with your relationships with family and social circle. For anything, please write more than 100 words!".

\section{EXPERIMENTAL USER STUDY}

We designed a four-day user study with 30 participants to compare the Diarybot chats with a Google doc baseline. The study ran from October $21^{\text {st }}$ to November $15^{\text {th }} 2019$.

\subsection{Participants}

An online ad was posted and circulated in a university campus in Seoul, Korea, for the duration of two weeks, from October $1^{\text {st }}$ 
to October $14^{\text {th }}, 2019$. The selection criteria were: (a) willingness to participate in writing about life's most difficult experiences; (b) having used Google document and KakaoTalk PC/Mobile for at least a week; and (c) ability to participate in a lab study for 4 consecutive days during the study period. We recruited a total of 30 participants $(14$ male, 16 female; Median $=28$ yrs, $\min =23$, $\max =41)$. All of them were native Korean, mostly undergraduate and graduate students from different disciplines. They were randomly assigned to one of the 3 writing conditions prior to the study, resulting in 10 participants in each condition.

\subsection{Task}

The study spanned across 4 days to keep with the original expressive writing setup [68]. To capture feedback on their experiences, participants were to complete surveys each day before and after the writing, and before and after the study. We also conducted a post-hoc interview to probe more deeply into their experiences. The entirety of activities spanned $\sim 120$ minutes per participant. All study sessions took place in a lab setting to keep the experimental setup consistent for all participants and to respond to any potential emergency immediately. Also, for easier writing and data protection, a laptop computer was used.

\subsection{Procedures}

Below the study procedures for the participants are detailed, and how the study session proceeded for four days.

Setting up the study. A quiet study room with a sizable desk, a comfortable chair, and a laptop was reserved for the study, also with some snacks. On each day, a friendly reminder of the study schedule was sent to the participants; if anything happened, they could flexibly reschedule time with the experimenter.

Informing the participants. When participants came in the first day, the experimenter shared a thorough introduction of the study, the purpose of expressive writing and study procedures before seeking the participant's voluntary, informed consent. If they felt uneasy about any of the procedure or at any point during the study, they could freely opt out. Should they decide to do so, their data would be discarded immediately. To ensure understanding, the experimenter reiterated the policy and procedures of the study to the participants each day to resolve any concerns and answer questions.

Protecting data privacy. Before participants gave their consent, it was made sure that they understood that their writings were to be collected and anonymized for linguistic analyses by the experimenter and by the experimenter only. To prevent any privacy breach, a blank Google doc was set up each day with the experimenter's account, and KakaoTalk PC app was logged in by a one-time-only access with a passcode sent to the participant's mobile and logged out at the end of each session. All data were collected on the study laptop that was only accessible to the experimenter. All procedures pertaining to managing, handling and storing data were approved by the institutional review board prior to the study.

Conducting the experiment. On the first day after the introductory session, participants filled out a pre-experiment and prewriting survey. They were then left in private to write. The writing took $\sim 20$ minutes each day. On their notice, the researcher came back to collect the post-writing survey. The same procedure was replicated in the following three days. On the last day, participants completed an additional post-experiment survey and took part in a semi-structured interview ( $\sim 20$ mins). At the completion of all activities, participants received a gift voucher equating to $\$ 20$ in value as compensation for their time.

\subsection{Safeguarding Study Participants and Ethics Approval}

To ensure the safety of all our participants, three steps were taken. Firstly, in the introductory session, it was made explicit to participants that they could leave the study at any time if they found any parts of the procedure difficult, or did not want to continue with the writing. Secondly, the lead author took precautions to read the writings immediately after each session to check for any indicators of distress or risky behavior that could be alarming, such as disclosures of self-harm or intend to harm others [62]. If this were the case, they would discuss with the participant an appropriate action to take, i.e. to consult the university's health support. Thankfully, no such instance occurred. Finally, at the beginning of each writing activity, the researcher reiterated the day's procedure and took questions to ensure the participant was not experiencing any confusion or uneasy health symptoms. The researcher's contact information was also provided in any case of emergency. The study and all its procedures and instruments were also carefully reviewed and approved by the institutional review board (IRB No. 1910/002-020).

\subsection{Data Collection and Analysis}

Writings from the study were collected for an analysis of stylistic difference. For a detailed understanding of the writing experiences in each condition, we employed a mixed-methods approach with surveys and interviews.

4.5.1 The Writing Data. Participant responses to the expressive writing instructions were first anonymized and then analyzed in terms of their use of affective and cognitive words with the Linguistic Inquiry and Word Count (LIWC), serviced in Korean translation $[45,87]$, to find any sentiment differences across writing conditions. To seek any difference in engagement, they were also reviewed according to Korean grammar in mood and style [42]: (a) whether the writing had an explicit addressee; and (b) stylistic differences that pertain to the final endings of a Korean sentence that reflect the attitude of a speaker to a listener.

4.5.2 Surveys. Surveys captured: (i) participants' psychological wellbeing pre-and post-study; (ii) writing activity and engagement, post-study; (iii) social acceptance of the technology used, poststudy; and (iv) participant interpretations of the past event, during the study.

Psychological wellbeing. To assess users' psychological wellbeing pre-and post-study, we used the 7-point Schwartz Outcome Scale (SOS-10; e.g., "I feel hopeful about my future.") [31] and 5-point Clinical Outcome in Routine Evaluation (CORE-10; e.g. "Over the last week, I felt unhappy.") [18]. Both are commonly used to measure wellbeing in a relatively short time frame $[2,5]$. The scores were 
computed for statistical analysis to find any difference pre- and post-study.

Writing activity and engagement. For overall activity and engagement, we added 4 items from Pennebaker's last day of writing questionnaire [66]: how personal, overall, the writings were; how much the writing expressed their feelings; how difficult it was to write the past four days; and how meaningful the study was. An additional item asked participants to briefly describe why they wrote what they wrote, on which we applied a content analysis method [35].

Social acceptance. To further investigate the user perceptions of the bot's social capabilities, we also added questions the social robot acceptance toolkit [32] on a 5-point Likert scale to measure the following constructs: Anxiety; Attention; Intention to Use; Perceived Adaptability, Enjoyment, Sociability and Usefulness; Social Influence; Social Presence; and Trust. We followed the path model in [32] to test its social acceptance hypotheses on Diarybot.

Interpretations. To measure the depth of subjective reappraisal, we designed a pair of items on a 7-point Likert scale to observe any significant impact of the follow-up prompts: "I could gain a new perspective on what I wrote." and "I could have a better understanding of what I wrote.". The questions were measured repeatedly within subjects every day during the study, as the follow-up prompts vary per text, and user experience may change over time. Yet because interpretation is a highly subjective notion, we investigate this in depth in the interviews.

4.5.3 Interviews. The study concluded with a semi-structured interview that asked participants about their overall writing experience; any psychological impact of the writing; and perceptions of the social disclosure with Diarybot. The interviews were audio recorded, anonymized, transcribed, and subjected to thematic analysis [7]. To this end, the lead author followed a repeated process of open coding and generated free-phrased labels [91], which were reviewed and renamed for initial codes. This process was repeated until the codes were refined to produce themes. We come up with three main themes from this analysis: how the design of Diarybot (i) invites impressions of one's emotional stories being listened to; (ii) promotes self-disclosure and reflection; and (iii) can better enhance continued engagement.

\section{FINDINGS}

Overall, participants chose to write about their most difficult setbacks in life, writing 178.5 words a day on average. For the total of 120 writings, a content analysis yielded topics that include: relationship matters (25.8\%), family crises (24.2\%), low self-esteem (14.2\%), failed love (10\%), failures (10\%), work stress $(9.2 \%)$ and other $(6.7 \%)$. Describing the reasons for why such topics were chosen, participants most often indicated that it presented a difficult or traumatic experience (39.2\%) or a recent trouble (19.2\%). They also described motivations to wrap up the study and earn closure (12.5\%), that it was the event that came to mind (9.2\%), to continue the narrative from the previous day (8.3\%), wanting to write about something that was never told (6.7\%). Few were non-specified (5\%).

Expressive writing offered participants a chance to look back on the past and reflect on it. Participants could share very personal stories $(M=6.20, \mathrm{SD}=0.89)$ and rated the experiment as meaningful $(\mathrm{M}=4.97, \mathrm{SD}=1.03)$. As for participants' psychological wellbeing, we did not find any significant difference (Table 4). Given the relatively short, four-day study period, we do not find this result surprising but natural. Though not measurable, subjective benefits such as self-reflection and insights were reported in the interviews, which will be detailed in the qualitative findings.

\subsection{Quantitative Findings}

Based on the writing and survey data, our results show differences in participant engagement in the three writing conditions, revealed from the narratives, social acceptance and personal reflections.

5.1.1 Diarybot Encourages Conversational Narratives. We hypothesized writing with a chatbot will encourage more social language. Our finding confirms the hypothesis as participant narratives with Diarybot show stylistic differences to be more conversational (Table 5). We examined the occurrences of conversational writings, i.e. writing addressed to someone (e.g. sentence final endings indicating an addressee, "Let me talk about this incident when I was in college."), as opposed to narratives that do not address anyone but the writers themselves (e.g. mood in descriptive form, "I think this writing is a meaningful opportunity for me to look back on myself in [omitted for privacy]). The chi-square goodness of fit shows a significant difference between the observed proportions across three conditions $\left(\chi^{2}=23.41, p<0.0001^{* * *}\right)$. Though Diarybot is not capable of a fully human-like conversation, these findings suggest that participants perceived their writing in either chat as a more conversational interaction, with Diarybot a virtual entity that they regarded capable of listening to their stories.

Furthermore, a one-way ANOVA and post-hoc Tukey test on word use in narratives by LIWC illustrates that in such conversational narratives, there is a significant difference in the use of affective words between baseline and Basic chat $\left(\mathrm{F}_{2,117}=4.59, p=0.01^{*}\right)$. This finding suggests the possibility that as participants felt like talking to Diarybot, they released the feelings with the event that they wrote about.

5.1.2 Basic Chat Mediates Ease and Expression, and Responsive Chat Social Acceptability. Next, increased interactivity via chatbot created more engaging and socially acceptable experience of writing. Our findings confirm H2-(a) for Basic chat. Writing with Diarybot was different from writing on a Google doc, as more natural engagement could be achieved. Our one-way ANOVA on post-study survey and post-hoc Tukey test show significantly less difficulty in writing $\left(\mathrm{F}_{2,27}=4.23, p=0.03^{*}\right)$ and more emotional expression $\left(\mathrm{F}_{2,27}=\right.$ $4.29, p=0.02^{*}$ ) were possible in Basic chat (Figure 4) compared to baseline. We found it interesting how it felt easier to write and able to express better in Basic chat without further interaction with the bot, coupled with the use of affective words from the LIWC result above. We conjecture that talking to Diarybot on a messenger app felt like a natural activity, and unlike Responsive chat that asked additional questions to the participants, Basic chat had less cognitive burden.

On the other hand, we confirm H2-(b) for Responsive chat. With respect to the two social hypotheses (see Table 6) in Heerink et al. [32], Responsive chat shows statistical significance in correlation and regression analyses: Perceived sociability is influenced by trust $\left(\mathrm{F}_{1,8}=10.7, \mathrm{p}<0.05^{*}, \mathrm{R}^{2}=.52\right)$; and social presence by perceived sociability $\left(\mathrm{F}_{1,8}=6.52, \mathrm{p}<0.05^{*}, \mathrm{R}^{2}=.38\right)$, where beta coefficients are .57 
"I wrote as if I were telling a story to someone I knew." Designing Chatbot Interactions for Expressive Writing in Mental Health

Table 4: Participants' average psychological wellbeing scores pre- and post-study. Standard deviations are reported in parentheses. Better wellbeing is indicated with higher SOS-10 (ranges 0-60) scores and lower CORE-10 (ranges 0-40) scores.

\begin{tabular}{llccc}
\hline \multicolumn{1}{c}{ Instrument } & \multicolumn{1}{c}{ Measured } & Baseline & Basic Chat & Responsive Chat \\
\hline SOS-10 & Pre-Study & $46.3(8.56)$ & $36.8(12.16)$ & $36.1(9.73)$ \\
& Post-Study & $47.3(5.70)$ & $38.7(12.16)$ & $35.1(10.89)$ \\
CORE-10 & Pre-Study & $10.2(3.55)$ & $14.2(4.92)$ & $16.7(6.13)$ \\
& Post-Study & $9.1(3.35)$ & $12.4(4.70)$ & $17.6(8.18)$ \\
\hline
\end{tabular}

Table 5: Stylistic differences in expressive writing narratives.

\begin{tabular}{lccc}
\hline \multicolumn{1}{c}{ Style } & Baseline & Basic Chat & Responsive Chat \\
\hline Descriptive & 40 & 27 & 16 \\
Conversational & 0 & 13 & 24 \\
\hline
\end{tabular}
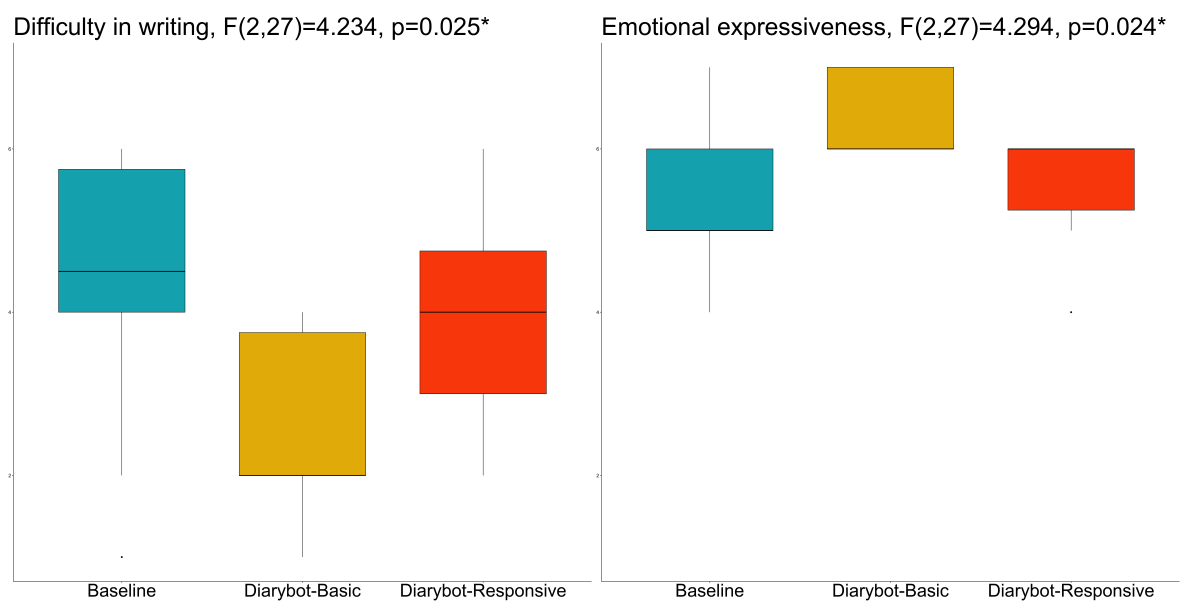

Figure 4: Boxplots of post-study responses to overall difficulty in writing and perceived emotional expression in it.

Table 6: Hypotheses and correlation scores.

\begin{tabular}{|c|c|c|c|c|c|}
\hline Condition & Hypothesis & Independent Variable & Dependent Variable & Pearson Correlation & $\begin{array}{l}\text { Significance } \\
\text { (2-tailed) }\end{array}$ \\
\hline \multirow[t]{2}{*}{ Basic Chat } & $\begin{array}{c}\text { PS is influenced by } \\
\text { Trust }\end{array}$ & Trust & $\begin{array}{l}\text { Perceived Sociability } \\
\text { (PS) }\end{array}$ & 0.61 & 0.06 \\
\hline & $\begin{array}{l}\text { SP is influenced by } \\
\text { SP }\end{array}$ & $\begin{array}{l}\text { Perceived Sociability } \\
\text { (PS) }\end{array}$ & Social Presence (SP) & 0.52 & 0.13 \\
\hline \multirow[t]{2}{*}{ Responsive Chat } & $\begin{array}{c}\text { PS is influenced by } \\
\text { Trust }\end{array}$ & Trust & $\begin{array}{c}\text { Perceived Sociability } \\
\text { (PS) }\end{array}$ & 0.76 & $0.01^{*}$ \\
\hline & $\begin{array}{l}\text { SP is influenced by } \\
\text { PS }\end{array}$ & $\begin{array}{l}\text { Perceived Sociability } \\
\text { (PS) }\end{array}$ & Social Presence (SP) & 0.67 & $0.03^{*}$ \\
\hline
\end{tabular}

$\left(\mathrm{p}<0.05^{*}\right)$, and $.72\left(\mathrm{p}<0.05^{*}\right)$, respectively (see Table 6 and Table 7$)$. We did not find statistical significance in social acceptability for Basic chat. It is likely that less interaction with the bot in Basic chat felt more mechanical, as participants mentioned in the interviews. This suggests that user perceptions of bot sociability may be influenced by the actual conversational exchanges with the agent.
5.1.3 Responsive Chat Prompts Offer Guidance. Interpretation is a subjective concept conceived differently by individuals. To test $\mathrm{H} 3$, we measured if writing with the follow-up prompts have had any significant impact as to change how participants made sense of their trauma. Two-way mixed ANOVAs on the survey data did not show significant results. In the interviews, though, Responsive 
Table 7: Hypotheses and regression results.

\begin{tabular}{|c|c|c|c|c|c|c|}
\hline Condition & $\begin{array}{l}\text { Independent } \\
\text { Variable }\end{array}$ & Dependent Variable & Beta Coefficient & $\mathrm{t}$ & $\begin{array}{l}\text { Significance } \\
\text { (2-tailed) }\end{array}$ & Adjusted $\mathrm{R}^{2}$ \\
\hline \multirow[t]{2}{*}{ Basic Chat } & Trust & $\begin{array}{l}\text { Perceived Sociability } \\
\text { (PS) }\end{array}$ & 0.35 & 2.15 & 0.06 & 0.29 \\
\hline & $\begin{array}{c}\text { Perceived } \\
\text { Sociability (PS) }\end{array}$ & Social Presence (SP) & 0.42 & 1.70 & 0.13 & 0.17 \\
\hline \multirow[t]{2}{*}{ Responsive Chat } & Trust & $\begin{array}{l}\text { Perceived Sociability } \\
\text { (PS) }\end{array}$ & 0.57 & 3.27 & $0.01^{*}$ & 0.52 \\
\hline & $\begin{array}{c}\text { Perceived } \\
\text { Sociability (PS) }\end{array}$ & Social Presence (SP) & 0.72 & 2.55 & $0.03^{*}$ & 0.38 \\
\hline
\end{tabular}

Table 8: Number of participants who had situated prompts, as opposed to default, template prompts, in Responsive chat.

\begin{tabular}{cccccc}
\hline Days with Responsive Prompts & 0 Day & 1 Day & 2 Days & 3 Days & 4 Days \\
\hline \# Participants & 2 & 4 & 2 & 1 & 1 \\
\hline
\end{tabular}

chat participants found prompts helpful in getting their thoughts in order and finding new insights. This finding suggests that regardless of the follow-up prompts, the primary experience of expressive writing may have persisted in all three conditions. We also note, however, that not all Responsive chat participants had responsive prompts throughout, due to our greedy chat algorithm that defaulted to the template prompts if no best match was found from the writing (Table 8). There were 2 participants who never had them; 4 participants having them only once; and 1 participant who had prompts dynamically changing upon her writing every day. Despite the limitation, participants readily made use of the prompts on their own, as we discuss further in qualitative findings.

\subsection{Qualitative Findings}

We now present qualitative findings from our interviews. As revealed in the quantitative findings above, perceived and learned affordances of each writing medium leads to distinctive writing experiences for our participants.

5.2.1 Socially Engaging with Diarybot. In the interviews, Basic and Responsive chat participants described that the writing experience was far from what writing on a notepad or in a journal would be like, because of having the bot in a conversation and the messenger app medium. P26 said, "I wrote as if I was telling a story to someone I knew." The affordance of a chatbot interface could lead the feeling of being attended to. P2 said he "really liked" the bot "cos it felt like I was talking to someone, but I really wasn't!" P19 described that "there's a difference between writing for yourself and for something in return; here you are writing 'to' someone.” P15 also agreed that "there's definitely the feeling that what I say does not vanish in the air, that it's not a monologue." P8, a middle-aged man, said that he started to "wait for this time of the day," though it was "a bit awkward" at first, because for people his age (41 years), talking about personal stories can be a rare chance. Such experiences invited perceptions in participants that they were "not alone" (P8).

We also find that the medium turned the writing experience into a conversation, as noted in previous research that the writing medium can shape the writing process [30]. In P29's words: "Let's say the notes app or a journal app. They give you a screen right there, telling you to "write." Now this is KakaoTalk. It's for communication. So it felt less a wkward for me to talk." P23 also said: "The fact that this was in KakaoTalk makes it, you know, we always use KakaoTalk to talk to people. So I did it just naturally as if I were talking to someone. Like, I didn't write ' haetseupnida' [honorific form of higher speech level] but ' haetso' [lower speech level]. That's how I did it. I think I did it that way because I just felt so. It wasn't a conscious thing, you know? That's what we are on KakaoTalk." Finally, P20, who didn't feel like Diarybot was actively listening to her, said, "Still, it's KakaoTalk. So there was definitely the feeling that I was speaking 'to' someone, or having a conversation."

Yet in Basic chat, there was not much in return. P17 said, "[after writing] that was it, just like that." They wanted more interaction to make it feel "less mechanical" (P10), e.g.: "analysis on my writing" (P17, P20), "follow up questions" (P17, P14) and "words of empathy, albeit not 'real" (P23, P8, P10), "encouragers" (P20), and "small talk" (P10). Some mentioned "conversation starters" (P10, P6, P17) and "fillers" (P4, P8, P14). For P14, an aspiring psychotherapist, the conversation could be set-up better to provide more constructive help: "What may be missing here would be, I think, that the bot just let me write. The bot may interrupt me, in a good sense, to catch something that I just let pass and point out where I am just too immersed in myself. You know in psychotherapy you've got to draw out more, maybe feelings, or help stay on a certain topic. That can be provided from the bot to provoke deeper thinking."

5.2.2 Enjoying and Adapting to Chatbot Performance. With respect to interactivity, Responsive chat had more favorable responses on its acceptance. Most Responsive chat participants found the interaction to be engaging, especially those who experienced changes in the prompts between template and responsive ones. P30 said, "I liked it, cos I had fun. [...] At first you just write as if you were writing a journal, but then I get something back, and more." They found it particularly pleasant that the prompts were "taken from the writing" 
(P16), which was found surprising by P28 as they were "contextbased" questions, which "(he) liked a lot" and thought "was really fun." Others said it helped the writing as it was "motivating" (P11), "[thoughts are] less scattered" (P19) and "engaging" (P29).

As is common for AI-enabled interactions with humans, the interactions invited participants to stay engaged and to figure out how the bot derived the prompts: "For the first two days, the questions were the same. It felt like they were almost a template. But on the third day, it picked up on someone I wrote about, and I was pleasantly, and honestly, surprised. So today I wrote more detail. I guess what I wrote for the past few days was pretty much the same, but how I felt about it, and approached it, changed" (P29). Others tried to help Diarybot find the right keyword, by making conscious alterations in their narratives to assist the bot in its recognition. P25 gave an interesting example: "For example, you can call a boyfriend 'him,'

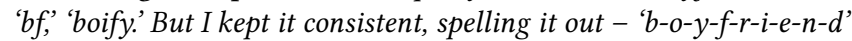
throughout." Similarly, P20 described his effort to assist the bot's performance: "It seemed like it wanted to talk about the people in my writing, so I wrote about people issues yesterday and today. But it didn't pick up. I am not sure if it is the way I wrote, or what I wrote about."

As the study progressed, however, participants' working knowledge of the bot's performance also increased, which reduced previously experienced surprise and enchantment with the interaction. For instance, P25 explains how initially surprising bot responses got weaned for her: "I've been doing this for four days. Now I go, 'well, if I write this, the bot will say that.' At first, I got excited with the bot asking me these questions because it felt like it was really following my story. But now, it feels like the bot asks me only because it is made to. Even if I write BANANA, BANANA, BANANA, maybe the bot will still ask the same? fust kidding. (laughter) What I'm saying is, the questions really gave me a huge epiphany at first. Now, it feels so routinized that I may just give meaningless responses in the end." P13 said, "What if the bot asked me other questions? The questions were pretty much the same. Maybe it can ask about something else, like, if I ever recovered, or what I've done to recover from it." P11 suggested: "What if there were more questions? If I were to talk about a friend, of course I may have given something and received something, but perhaps it has something else to do with the friend. It might be better if I could get those personalized questions."

Also, not all Responsive chat participants had the smart, responsive prompts but default, template prompts (Table 8). Participants who experienced repetition of the same prompts concluded that the interaction was static (P29): "Well, I thought, the system is not THAT intelligent. But I mean, I don't even know if the system 'learns' anything, so I was not disappointed, not really, but, maybe it's only a machine after all." Likewise, P22 commented on the order of prompts: "It felt less and less like having a conversation. After a day and two, the questions came out in the same order. So I thought it's templates, not dynamic."

5.2.3 Subjective Benefits from Chat Interaction. Basic chat received mixed feedback from participants, who expressed the desire for having more interaction with the bot, but appreciated the opportunity to disclose. P2, who had never had any emotional writing experience before, was willing to have Diarybot to be his "secret means of communication" to which he could say things that he never told others. Also, some participants expressed liking that they could "just come find Diarybot when [they] want to talk, but there's no one to talk to" (P29). Here, having someone to talk to about an emotional experience is related to the belief [93] that sharing emotions with others is perceived to be beneficial, whether it leads to actual recovery or not. For them, chatting also felt easier than writing. P10 noted: "It was not like writing out everything that happened, but telling a story." P17 also said that she could "pour out" to Diarybot, while she would rather compose herself for a blog entry. They also described it helped to "talk naturally," (P17), "comfortably" (P26), and "honestly" (P20).

Follow-up prompts in the Responsive chat, on the other hand, encouraged self-reflection that furthered insight on their writing. They led them to approach Diarybot to "share [their] problem" (P11) and for P30, to "explain what happened, rather than only seeking consolation, like [she] would from [her] friends." P12 said she liked the prompts because: "It felt like those questions really got me to talk about some things that I missed in the writing." Likewise, for P19: "Yesterday, [the bot] asked me about something that I never thought about, and I really liked that." The prompts helped "get things sorted out" (P16) as if it were "a professional procedure, like a therapy session" (P11). Others agreed that the prompts "really was an opportunity to think from an objective perspective" (P30) and "help organize, or take steps, in my thought process" (P12). In P28's words: "Well, I think it helps me look at the things from a perspective, or from a distance. Ideally, you'd tell somebody to get that. But that is, nay, troublesome, cos you gotta tell the person. That's too personal, you know? So the bot was helpful in that regard. Also, I get trapped inside my own thinking. Cos I am on MY side, right? I think the bot could enlighten me." Even if the same prompts were repeated for P11, they took different meaning for her: "Some questions were repeated. But in the context of each day's writing they meant different to me. I felt they were a very efficient means to draw out what I have, to look at what I had inside."

Even if the prompt was repeated, some participants took the liberty of making it serve their best purpose. For example, the last follow-up question on self-awareness was the same in both template and responsive sets but was relatively open-ended in nature. P11 said she "loved" it, as it was "[her] private self-encouragement." For P30 also, "it felt like a chance to take care of [herself]." Alternatively, they had it fit to their own context. P12 said: "I'd write about all these things with the bot. Then I would arrive at the last question whether to console myself, or to think further about it." P30 used it to set up her resolution: "I really liked it here. It was like, 'okay, so now I've got to be 'blah' today.' I wish that process were a bit longer."

\section{DISCUSSION}

This work delves into the social disclosure of emotions with chatbots. To investigate the interaction and user experience, we designed Diarybot, a chatbot assistant for expressive writing. We've asked how chatbots may impact user writing, engagement and reflection of the past. Findings from our study reveal that writing with Diarybot invited conversational narratives, suggesting that the bot can be perceived as a social entity in emotional disclosure. Participants felt less difficult and more capable of emotional expression when they were invited to write to a bot, though more 
interactivity via follow-up led the bot's perceived sociability and social presence. The follow-up chat was well received for subjective benefits of self-reflection and insights, yet the repeated-ness of prompts were not particularly to participants' liking. We now discuss the findings in the context of designing social disclosure with chatbots for mental wellbeing.

\subsection{From Writing to Telling Stories}

So far, expressive writing has hardly been studied as a social interaction with a machine. Our findings show written emotional disclosure can be made to chatbots, and doing so encourages writing in a narrative format. Narratives of participants who used Diarybot mostly assumed an audience as if in a conversation. This suggests chatbots as a design opportunity for expressive writing and its adaptations. In an early work, Pennebaker [68] has noted that people have a tendency to seek out meaning in life, and that forming a story plays a major role in driving health benefits of expressive writing, like so in talking to a psychotherapist or in narrative psychology (e.g. [14, 68, 70, 85]). Pennebaker's continued research effort in investigating the underlying mechanism as to how writing heals has arrived at the Linguistic Inquiry and Word Count (LIWC; i.e. [87]). The analysis of writings people wrote revealed that the use of more positive emotions, as well as insight and causal words, has promise linked to benefit. In forming a story, an individual's emotional reactions to stress and trauma tend to achieve coherence and structure, both elements of a good narrative [68].

How can we, then, encourage people to write a story on their trauma, especially so that it does not fall into a distorted recollection or a repeated venting loop? Our work shows that chatbots can provide an answer. In the writing activity, the user expectations and affordances of the chatting screen and the virtual presence of a bot invite a two-way interaction, i.e. conversation, which enables telling a story instead of writing a stream of consciousness. Unlike emotional writing, stories often require coherence, with structure, use of causal explanation, repetition of themes, and an appreciation of the listener's perspective $[12,68]$. Putting stress in words, especially in an orderly and coherent manner, is therefore required in conversations [43]. While one may form a story by writing alone, engaging with chatbots can ensue the interactivity that triggers a social activity, e.g. to "explain what happened" (P30). With careful design and safeguarding measures for privacy, we believe our work shows the potential of chatbots to provide the unobtrusive help that a writer needs for expressive writing to lead benefit.

In our work, however, we did not find significant difference in the use of causal and insightful words in participant narratives but affective word use. While word use may contribute to the making of a narrative, it may or may not entirely explain how one writes. Future work should investigate any further stylistic and structural differences in expressive writing with and without an agent, and their relationship to wellbeing.

\subsection{User Perceptions of and Expectations for Sociality}

Diarybot's Basic and Responsive chats resulted in different writing experiences, quite expectedly, yet highlighting the implications of chat interaction design. In our findings, Basic chat participants were found with less perceived difficulty in writing and their narratives more emotionally expressive than the baseline. However, social acceptance was associated with Responsive chat, suggesting that participants attributed sociability to conversational exchanges with the bot, rather than the bot itself. While it might have felt more convenient to talk in Basic chat, it did not feel interactive enough as if a real conversation. For Basic chat participants, writing without further interaction with the bot eventually led them to find the interaction almost identical to writing on a notepad.

Interactivity in Responsive chat led engagement, as participants were eager to find what the bot would say to their writing especially after they learned the prompts could change. However, the smart, responsive prompts were designed in a greedy manner that some participants only had template prompts repeatedly. In fact, the design decision was made to avoid contextual failure, for a wrong choice of keywords could deter user experience. Even if they worked, those who had the responsive prompts tried to decode the chat algorithm. Participants actively made guesses in their narratives, and in time, assumed knowledge, which reduced their initial excitement and engagement.

Taken together, we show that chatbots have a clear user expectation that they have a certain level of intelligence to engage in a two-way conversation, in a manner that suggests the bot's thinking. In Rimé's affective and cognitive route of sharing emotions [75], the reactions on the listener's part are always expected, e.g. warm words of consolation or helping to come to terms with the feelings. Learning that prompts will probably be repeated and what keywords will be replaced creates a predictable interaction outcome, which may defy the expectations in engaging in social disclosure of emotions. Although system predictability is required for consistent user experience and trust [19], in human-computer communication, it may only seem that the bot does not understand [38, 78]. While both types of chat can provide a space for expressive writing, no further interaction in Basic chat can only provide one-sided interaction where the writer does the telling but not sharing. Situated prompts in Responsive chat are useful, but any signs of mechanical workings, e.g. templates and repeated-ness, may risk poor bot intelligence to keep up with the changing conversational context [28].

It is yet unthinkable in our time that chatbots engage in a fully natural conversation. To calibrate user expectations, it is advised to inform users of what the bot's capable of (e.g. [55]). This is relatively easier for task-based conversational agents, since for tasks, user intentions and linguistic entities in conversation are clear and can be predefined. However, in the context of mental health and emotional recovery, pragmatics of conversational interaction is a tough challenge, and disclosers themselves sometimes have a hard time telling their own stories. While our findings suggest participants were willing to engage with Diarybot and can tell the bot stories, without conversational exchanges with due intelligence the engagement may not last longer. We move on to our final thoughts on the design of bot messages to lead benefit for expressive writing.

\subsection{Encouraging Constructive Storytelling}

Responsive chat was designed with situated prompts to follow up with what users wrote, which participants appreciated for benefits of self-reflection and insights. As learned from Rimé's work [75], the 
underlying assumption for the design was that in a social setting, disclosers are prone to sharing emotional reactions rather than trying to construct a meaning. Thus prompts were intended and crafted for writers to achieve a cognitive understanding, asking to review feelings and answer questions for interpretation. However, such an understanding is a subjective notion and a process-like concept that is difficult to pinpoint or measure.

Hence we asked if the writing caused a significant turnaround of the traumatic event, to see if the prompts might have had such an impact. Participants reported in a comparable manner with respect to post-writing assessments in the survey. However, subjective benefits were reported for Responsive chat where prompts helped to mentalize and get thoughts in order. We ponder two possible explanations. First, as noted earlier, participants may not have had a full engagement with the prompts as they learned how the bot worked in Responsive chat. However, this does not fully explain the qualitative findings. The second possibility, then, is that the follow-up could provide guidance to review their thought process, rather than drive change in how they interpreted the past entirely. This can explain the little difference in post-writing across all conditions. In line with previous research that forming a story matters in expressive writing $[14,68,70,80,85]$, we suggest that it lies in the process of writing a narrative that disclosers grow capable of accounting for the past trauma, and in doing so the bot can help them organize their thoughts in a coherent manner.

This opens up new opportunities in the design of expressive writing as a social interaction. Chatbots can provide a social environment for expressive writers, where they can tell their stories freely without fear of stigma and losing privacy. Interactions with the bot can be designed as guidance to encourage constructive storytelling, e.g. to maintain focus and goal, and put events in order [68]. Several other ideas come up. Follow-up can be designed for the writer to review the writing and reflect the musings to the next session. Or, it can be in the form of a report on the writing in terms of the use of pronouns and word count. Taking further, with the help of AI, the bot may provide real-time writing-driven insights by scoring emotionality and structuredness, identifying key elements of the narrative and stylistic consistency.

Outside the writing realm, chatbots have popularized computerized treatment and cost-effective psychotherapy [95]. Oftentimes, however, what the bot says replicate therapist-like skills and treatment techniques. There are AI-generated therapy chats (e.g. $[16,56])$, but it seems a long way until they are fully well-received [56]. When therapeutic writing becomes therapeutic discourse, the implicit social agreement is carried on to the bot to make joint endeavor in meaning-making, i.e. to re-author a personal history and re-organize memories, beliefs and cognitions [50]. Therefore we believe conversation design will be more responsible for what users make out of the interaction in a long-term engagement. Coupled with advanced NLP techniques, a number of hopeful possibilities and opportunities arise. We are excited by future prospects on conversational agents that help users tell their stories to heal, promising safety, protection and wellbeing.

\section{LIMITATIONS AND FUTURE WORK}

We have to acknowledge that there are several limitations to this study with respect to the original expressive writing setup. Expressive writing is usually studied for a longer duration, sometimes with a weeks' and months' follow-up, to study any health benefit. Plus, we have no way of verifying participants' true intent in disclosure when we invited them to write about life's most troubled, or traumatic, event, but only their voluntary consent in doing so. Also, writing in a lab setting may influence sensitivities in emotional disclosure. While remote writing was considered as a more natural setup, we chose otherwise to keep the experiment setting consistent for all participants and to control for any unexpected emergency due to intense emotional disclosure. Finally, while the original writing instructions do not require a length requirement, we did to ensure algorithmic chat performance. As for the chat interaction, a couple of participants never had the responsive prompts, and some pointed out redundancy in bot prompts. In preparation of this scenario, we had designed template prompts and 5 sets of synonymous prompts. For more dynamic conversation, we plan to design a bot assistant that follows up on the previous day's writing, and that invites to reflect on different subjects instead of reflecting on one key person only. While others have used Wizard-of-Oz [33] for a social setting of expressive writing, we are keen to investigate a chatbot interaction with the current state-of-the-art technology to evaluate social disclosure with $\mathrm{AI}$ in a more technologically realistic setting.

\section{CONCLUSION}

This study designed and implemented an interactive writing assistant in a chatbot interface called Diarybot to investigate user experience of social disclosure with a chatbot. We studied two chat versions of the bot: Basic and Responsive. Our findings from a user study with 30 participants suggest that Diarybot can support social sharing of emotions: Writing with Diarybot motivated to write conversational narratives, and while Basic chat felt easier and more emotionally expressible, Responsive chat mediated social acceptance and subjective benefits of self-reflection and insight. It is however cautioned that the bot display sufficient humanlike intelligence to follow up with what users write. We discuss design implications of social disclosure with conversational agents to encourage constructive storytelling.

\section{ACKNOWLEDGMENTS}

This research was supported by Young Medical Scientist Research Grant through the Daewoong Foundation (DS185) in Seoul, Korea. It is also indebted to all anonymous reviewers who shared constructive feedback and words of wisdom. Much appreciation is dedicated to our study participants who willingly and courageously shared the most difficult experiences from their past for the study.

\section{REFERENCES}

[1] Irwin Altman. 1975. The Environment and Social Behavior: Privacy, Personal Space, Territory, and Crowding. (1975)

[2] Michael Barkham, Bridgette Bewick, Tracy Mullin, Simon Gilbody, Janice Connell, Jane Cahill, John Mellor-Clark, David Richards, Gisela Unsworth, and Chris Evans. 2013. The CORE-10: A short measure of psychological distress for routine use in the psychological therapies. Counselling and Psychotherapy Research 13, (January 2013), 1-13. 
[3] T. W. Bickmore, L. Caruso, K. Clough-Gorr, and T. Heeren. 2005. 'It's just like you talk to a friend' relational agents for older adults. Interacting with Computers 17, 6 (December 2005), 711-735. DOI:https://doi.org/10.1016/j.intcom.2005.09.002

[4] Timothy Bickmore and Amanda Gruber. 2010. Relational agents in clinical psychiatry. Harvard Review of Psychiatry 18, 2 (March 2010), 119-130. DOI:https: //doi.org/10.3109/10673221003707538

[5] Mark A. Blais, William R. Lenderking, Lee Baer, Ashley deLorell, Kathleen Peets, Linda Leahy, and Craig Burns. 1999. Development and Initial Validation of a Brief Mental Health Outcome Measure. Fournal of Personality Assessment 73, 3 (December 1999), 359-373. DOI:https://doi.org/10.1207/S15327752JPA7303_5

[6] Mark Bond and James W. Pennebaker. 2012. Automated computer-based feedback in expressive writing. Computers in Human Behavior 28, 3 (May 2012), 1014-1018. DOI:https://doi.org/10.1016/j.chb.2012.01.003

[7] Virginia Braun and Victoria Clarke. 2006. Using thematic analysis in psychology. Qualitative Research in Psychology 3, 2 (January 2006), 77-101. DOI:https://doi. org/10.1191/1478088706qp063oa

[8] Gillian Butler, Melanie Fennell, Philip Robson, and Michael Gelder. 1991. Comparison of behavior therapy and cognitive behavior therapy in the treatment of generalized anxiety disorder. Fournal of Consulting and Clinical Psychology 59, 1 (1991), 167-175. DOI:https://doi.org/10.1037/0022-006X.59.1.167

[9] Gillian Cameron, David Cameron, Gavin Megaw, R. R. Bond, Maurice Mulvenna, Siobhan O'Neill, C. Armour, and Michael McTear. 2018. Best practices for designing chatbots in mental healthcare - A case study on iHelpr. In Proceedings of the 32nd International BCS Human Computer Interaction Conference (HCI-2018) DOI:http://dx.doi.org/10.14236/ewic/HCI2018.129

[10] L. D. Cameron and G. Nicholls. 1998. Expression of stressful experiences through writing: effects of a self-regulation manipulation for pessimists and optimists Health Psychol 17, 1 (January 1998), 84-92. DOI:https://doi.org/10.1037//02786133.17.1.84

[11] Véronique Christophe and Bernard Rimé. 1997. Exposure to the social sharing of emotion: Emotional impact, listener responses and secondary social sharing. European fournal of Social Psychology 27, 1 (1997), 37-54. DOI:https://doi.org/10 1002/(SICI)1099-0992(199701)27:1<37::AID-EJSP806>3.0.CO;2-1

[12] Leslie F. Clark. 1993. Stress and the Cognitive-Conversational Benefits of Social Interaction. Fournal of Social and Clinical Psychology 12, 1 (March 1993), 25-55. DOI:https://doi.org/10.1521/jscp.1993.12.1.25

[13] Jorden Cummings, D. Saint, and Jeff Park. 2014. Expressive Writing in Psychotherapy: A Tool to Promote and Track Therapeutic Change. Professional Psychology: Research and Practice 45, (October 2014), 378-386. DOI:https://doi.org/10.1037/ a0037682

[14] Sharon Danoff-Burg, Catherine E. Mosher, Asani H. Seawell, and John D. Agee 2010. Does narrative writing instruction enhance the benefits of expressive writing? Anxiety, Stress, \& Coping 23, 3 (May 2010), 341-352. DOI:https://doi.org/ 10.1080/10615800903191137

[15] David DeVault, Ron Artstein, Grace Benn, Teresa Dey, Ed Fast, Alesia Gainer Kallirroi Georgila, Jon Gratch, Arno Hartholt, Margaux Lhommet, Gale Lucas, Stacy Marsella, Fabrizio Morbini, Angela Nazarian, Stefan Scherer, Giota Stratou, Apar Suri, David Traum, Rachel Wood, Yuyu Xu, Albert Rizzo, and Louis-Philippe Morency. 2014. SimSensei kiosk: A virtual human interviewer for healthcare decision support. In Proceedings of the 2014 International Conference on Autonomous Agents and Multi-agent Systems (AAMAS '14), Richland, SC, 1061-1068.

[16] Dongkeon Lee, Kyo-Joong Oh, and Ho-Jin Choi. 2017. The chatbot feels you - a counseling service using emotional response generation. In 2017 IEEE International Conference on Big Data and Smart Computing (BigComp), IEEE, Jeju Island, South Korea, 437-440. DOI:https://doi.org/10.1109/BIGCOMP.2017.7881752

[17] Daniel A. Donnelly and Edward J. Murray. 1991. Cognitive and Emotional Changes in Written Essays and Therapy Interviews. Fournal of Social and Clinical Psychology 10, 3 (September 1991), 334-350. DOI:https://doi.org/10.1521/jscp. 1991.10.3.334

[18] Chris Evans, John Mellor-Clark, Frank Mar. 2000. CORE: Clinical Outcomes in Routine Evaluation. Journal of Mental Health 9, 3 (January 2000), 247-255. DOI:https://doi.org/10.1080/jmh.9.3.247.255

[19] World Leaders in Research-Based User Experience. 10 Usability Heuristics for User Interface Design. Nielsen Norman Group. Retrieved January 11, 2021 from https://www.nngroup.com/articles/ten-usability-heuristics/

[20] Kathleen Kara Fitzpatrick, Alison Darcy, and Molly Vierhile. 2017. Delivering cognitive behavior therapy to young adults with symptoms of depression and anxiety using a fully automated conversational agent (Woebot): A randomized controlled trial. $7 M I R$ Ment Health 4, 2 (June 2017). DOI:https://doi.org/10.2196/ mental.7785

[21] Joanne Frattaroli. 2006. Experimental disclosure and its moderators: a metaanalysis. Psychol Bull 132, 6 (November 2006), 823-865. DOI:https://doi.org/10. 1037/0033-2909.132.6.823

[22] Kenneth J. Gergen and Mary M. Gergen. 1988. Narrative and the Self as Relationship. In Advances in Experimental Social Psychology, Leonard Berkowitz (ed.) Academic Press, 17-56. DOI:https://doi.org/10.1016/S0065-2601(08)60223-3

[23] Erving Goffman. 2009. Stigma: Notes on the Management of Spoiled Identity. Simon and Schuster.
[24] Oscar F. Gonçalves. 1994. Cognitive Narrative Psychotherapy: The Hermeneutic Construction of Alternative Meanings. Journal of Cognitive Psychotherapy; New York 8, 2 (1994), 105-108,110-125.

[25] Eva-Maria Gortner, Stephanie S. Rude, and James W. Pennebaker. 2006. Benefits of Expressive Writing in Lowering Rumination and Depressive Symptoms. Behavior Therapy 37, 3 (September 2006), 292-303. DOI:https://doi.org/10.1016/j.beth.2006. 01.004

[26] Maria C. Graf, Brandon A. Gaudiano, and Pamela A. Geller. 2008. Written emotional disclosure: A controlled study of the benefits of expressive writing homework in outpatient psychotherapy. Psychotherapy Research 18, 4 (July 2008), 389-399. DOI:https://doi.org/10.1080/10503300701691664

[27] M. A. Greenberg, C. B. Wortman, and A. A. Stone. 1996. Emotional expression and physical health: revising traumatic memories or fostering self-regulation? $\mathrm{F}$ Pers Soc Psychol 71, 3 (September 1996), 588-602. DOI:https://doi.org/10.1037//00223514.71.3.588

[28] H. P. Grice. 1975. Logic and Conversation. Speech Acts (December 1975), 41-58. DOI:https://doi.org/10.1163/9789004368811_003

[29] Adam J. Guastella and Mark R. Dadds. 2006. Cognitive-Behavioral Models of Emotional Writing: A Validation Study. Cogn Ther Res 30, 3 (June 2006), 397-414. DOI:https://doi.org/10.1007/s10608-006-9045-6

[30] Christina Haas. 1989. How the Writing Medium Shapes the Writing Process: Effects of Word Processing on Planning. Research in the Teaching of English 23, 2 (1989), 181-207.

[31] Greg Haggerty, Margaret Blake, Melissa Naraine, Caleb Siefert, and Mark A. Blais. 2010. Construct validity of the Schwartz outcome scale-10: comparisons to interpersonal distress, adult attachment, alexithymia, the five-factor model, romantic relationship length and ratings of childhood memories. Clin Psychol Psychother 17, 1 (February 2010), 44-50. DOI:https://doi.org/10.1002/cpp.643

[32] Marcel Heerink, Ben Krose, Vanessa Evers, and Bob Wielinga. 2009. Measuring acceptance of an assistive social robot: a suggested toolkit. In RO-MAN 2009 The 18th IEEE International Symposium on Robot and Human Interactive Communication, IEEE, Toyama, Japan, 528-533. DOI:https://doi.org/10.1109/ROMAN. 2009.5326320

[33] Annabell Ho, Jeff Hancock, and Adam S Miner. 2018. Psychological, Relational, and Emotional Effects of Self-Disclosure After Conversations With a Chatbot. $\mathcal{F}$ Commun 68, 4 (August 2018), 712-733. DOI:https://doi.org/10.1093/joc/jqy026

[34] Andrea B. Horn, Patrick Pössel, and Martin Hautzinger. 2011. Promoting Adaptive Emotion Regulation and Coping in Adolescence: A School-based Programme. 7 Health Psychol 16, 2 (March 2011), 258-273. DOI:https://doi.org/10. $1177 / 1359105310372814$

[35] Hsiu-Fang Hsieh and Sarah E. Shannon. 2005. Three Approaches to Qualitative Content Analysis. Qual Health Res 15, 9 (November 2005), 1277-1288. DOI:https: //doi.org/10.1177/1049732305276687

[36] Stephen S. Ilardi and W. Edward Craighead. 1994. The Role of Nonspecific Factors in Cognitive-Behavior Therapy for Depression. Clinical Psychology: Science and Practice 1, 2 (1994), 138-155. DOI:https://doi.org/10.1111/j.14682850.1994.tb00016.x

[37] Becky Inkster, Shubhankar Sarda, and Vinod Subramanian. 2018. An EmpathyDriven, Conversational Artificial Intelligence Agent (Wysa) for Digital Mental Well-Being: Real-World Data Evaluation Mixed-Methods Study. 7 MIR mHealth and uHealth 6, 11 (2018), e12106. DOI:https://doi.org/10.2196/12106

[38] Baptiste Jacquet, Jean Baratgin, and Frank Jamet. 2019. Cooperation in Online Conversations: The Response Times as a Window Into the Cognition of Language Processing. Front. Psychol. 10, (2019). DOI:https://doi.org/10.3389/fpsyg. 2019.00727

[39] Jin-pyo Hong and Jung-won Cha. 2009. Retrieving Important Sentences in Korean using TextRank Algorithm. Communications of the Korean Institute of Information Scientists and Engineers 36, 1C (June 2009), 311-314.

[40] James C. Kaufman and Janel D. Sexton. 2006. Why Doesn't the Writing Cure Help Poets?: Review of General Psychology (September 2006). Retrieved September 14, 2020 from https://journals.sagepub.com/doi/10.1037/1089-2680.10.3.268

[41] Junhan Kim, Yoojung Kim, Byungjoon Kim, Sukyung Yun, Minjoon Kim, and Joongseek Lee. 2018. Can a Machine Tend to Teenagers' Emotional Needs? A Study with Conversational Agents. In Extended Abstracts of the 2018 CHI Conference on Human Factors in Computing Systems (CHI EA '18), Association for Computing Machinery, New York, NY, USA, 1-6. DOI:https://doi.org/10.1145/ 3170427.3188548

[42] Korean Language and Literature Compilation Committee. 2000. Historical Materials and Encyclopedia of Korean Language Literature. Korean Dictionary Researcher, Seoul, Korea.

[43] William Labov and David Fanshel. 1977. Therapeutic Discourse: Psychotherapy as Conversation. Academic Press.

[44] Helmut Lang, Melina Klepsch, Florian Nothdurft, Tina Seufert, and Wolfgang Minker. 2013. Are computers still social actors? In CHI '13 Extended Abstracts on Human Factors in Computing Systems (CHI EA '13), Association for Computing Machinery, New York, NY, USA, 859-864. DOI:https://doi.org/10.1145/2468356. 2468510 
[45] Sang Won Lee, Inyeop Kim, Jaehyun Yoo, Sungkyu Park, Bumseok Jeong, and Meeyoung Cha. 2016. Insights from an expressive writing intervention on Facebook to help alleviate depressive symptoms. Computers in Human Behavior 62, (September 2016), 613-619. DOI:https://doi.org/10.1016/j.chb.2016.04.034

[46] Stephen J. Lepore and Joshua M. Smyth. 2002. The Writing Cure: How Expressive Writing Promotes Health and Emotional Well-being. American Psychological Association.

[47] Olivia T. Lestideau and Loraine F. Lavallee. 2007. Structured writing about current stressors: The benefits of developing plans. Psychology \& Health 22, 6 (August 2007), 659-676. DOI:https://doi.org/10.1080/14768320601176089

[48] Gale M. Lucas, Jonathan Gratch, Aisha King, and Louis-Philippe Morency. 2014 It's only a computer: Virtual humans increase willingness to disclose. Computers in Human Behavior 37, (August 2014), 94-100. DOI:https://doi.org/10.1016/j.chb. 2014.04.043

[49] Haiwei Ma, Estelle Smith, Lu He, Saumik Narayanan, Robert Giaquinto, Roni Evans, Linda Hanson, and Svetlana Yarosh. 2017. Write for Life: Persisting in Online Health Communities through Expressive Writing and Social Support Proceedings of the ACM on Human-Computer Interaction 1, (December 2017), 1-24. DOI:https://doi.org/10.1145/3134708

[50] Christopher Marx, Cord Benecke, and Antje Gumz. 2017. Talking Cure Models: A Framework of Analysis. Front Psychol 8, (September 2017). DOI:https://doi.org/ 10.3389/fpsyg.2017.01589

[51] Erin L. Merz, Rina S. Fox, and Vanessa L. Malcarne. 2014. Expressive writing interventions in cancer patients: a systematic review. Health Psychol Rev 8, 3 (2014), 339-361. DOI:https://doi.org/10.1080/17437199.2014.882007

[52] Rada Mihalcea and Paul Tarau. 2004. TextRank: Bringing Order into Text. In Proceedings of the 2004 Conference on Empirical Methods in Natural Language Processing, Association for Computational Linguistics, Barcelona, Spain, 404-411. Retrieved January 20, 2020 from https://www.aclweb.org/anthology/W04-3252

[53] Adam Miner, Amanda Chow, Sarah Adler, Ilia Zaitsev, Paul Tero, Alison Darcy, and Andreas Paepcke. 2016. Conversational Agents and Mental Health: TheoryInformed Assessment of Language and Affect. In Proceedings of the Fourth International Conference on Human Agent Interaction (HAI '16), Association for Computing Machinery, Biopolis, Singapore, 123-130. DOI:https://doi.org/10.1145/ 2974804.2974820

[54] Adam S. Miner, Nigam Shah, Kim D. Bullock, Bruce A. Arnow, Jeremy Bailenson, and Jeff Hancock. 2019. Key Considerations for Incorporating Conversational AI in Psychotherapy. Front Psychiatry 10, (October 2019). DOI:https://doi.org/10. 3389/fpsyt.2019.00746

[55] Robert J. Moore. 2018. A Natural Conversation Framework for Conversational UX Design. In Studies in Conversational UX Design, Robert J. Moore, Margaret H. Szymanski, Raphael Arar and Guang-Jie Ren (eds.). Springer International Publishing, Cham, 181-204. DOI:https://doi.org/10.1007/978-3-319-95579-7_9

[56] Robert R. Morris, Kareem Kouddous, Rohan Kshirsagar, and Stephen M. Schueller. 2018. Towards an Artificially Empathic Conversational Agent for Mental Health Applications: System Design and User Perceptions. Fournal of Medical Internet Research 20, 6 (2018), e10148. DOI:https://doi.org/10.2196/10148

[57] Clifford Nass, Jonathan Steuer, and Ellen R. Tauber. 1994. Computers are social actors. In Conference Companion on Human Factors in Computing Systems (CHI '94), Association for Computing Machinery, Boston, Massachusetts, USA, 204 DOI:https://doi.org/10.1145/259963.260288

[58] Kate G. Niederhoffer and James W. Pennebaker. 2009. Sharing one's story: On the benefits of writing or talking about emotional experience. In Oxford handbook of positive psychology, 2nd ed. Oxford University Press, New York, NY, US, 621-632.

[59] Frédéric Nils and Bernard Rimé. 2012. Beyond the myth of venting: Social sharing modes determine the benefits of emotional disclosure. European fournal of Social Psychology 42, 6 (2012), 672-681. DOI:https://doi.org/10.1002/ejsp.1880

[60] Ivan Nyklíček, Ad Vingerhoets, and Marcel Zeelenberg. 2007. Emotion Regulation: Conceptual and Clinical Issues. Springer Science \& Business Media.

[61] William T. O’Donohue and Jane E. Fisher. 2009. General Principles and Empirically Supported Techniques of Cognitive Behavior Therapy. John Wiley \& Sons.

[62] Kathleen O'Leary, Stephen M. Schueller, Jacob O. Wobbrock, and Wanda Pratt. 2018. "Suddenly, we got to become therapists for each other": Designing Peer Support Chats for Mental Health. In Proceedings of the 2018 CHI Conference on Human Factors in Computing Systems (CHI '18), Association for Computing Machinery, Montreal QC, Canada, 1-14. DOI:https://doi.org/10.1145/3173574. 3173905

[63] SoHyun Park, Jeewon Choi, Sungwoo Lee, Changhoon Oh, Changdai Kim, Soohyun La, Joonhwan Lee, and Bongwon Suh. 2019. Designing a Chatbot for a Brief Motivational Interview on Stress Management: Qualitative Case Study. Fournal of Medical Internet Research 21, 4 (2019), e12231. DOI:https: //doi.org/10.2196/12231

[64] J. W. Pennebaker. 2000. Telling stories: the health benefits of narrative. Lit Med 19, 1 (2000), 3-18. DOI:https://doi.org/10.1353/lm.2000.0011

[65] J. W. Pennebaker and S. K. Beall. 1986. Confronting a traumatic event: toward an understanding of inhibition and disease. F Abnorm Psychol 95, 3 (August 1986), 274-281. DOI:https://doi.org/10.1037//0021-843x.95.3.274

[66] J. W. Pennebaker, M. Colder, and L. K. Sharp. 1990. Accelerating the coping process f Pers Soc Psychol 58, 3 (March 1990), 528-537. DOI:https://doi.org/10.1037//0022-
3514.58.3.528

[67] J. W. Pennebaker, T. J. Mayne, and M. E. Francis. 1997. Linguistic predictors of adaptive bereavement. F Pers Soc Psychol 72, 4 (April 1997), 863-871. DOI:https: //doi.org/10.1037//0022-3514.72.4.863

[68] J. W. Pennebaker and J. D. Seagal. 1999. Forming a story: the health benefits of narrative. 7 Clin Psychol 55, 10 (October 1999), 1243-1254. DOI:https://doi.org/10. 1002/(SICI)1097-4679(199910)55:10<1243::AID-JCLP6>3.0.CO;2-N

[69] James W. Pennebaker. 1997. Writing About Emotional Experiences as a Therapeutic Process. Psychol Sci 8, 3 (May 1997), 162-166. DOI:https://doi.org/10.1111/ j.1467-9280.1997.tb00403.x

[70] James W. Pennebaker. 2000. Telling Stories: The Health Benefits of Narrative. Literature and Medicine 19, 1 (May 2000), 3-18. DOI:https://doi.org/10.1353/lm. 2000.0011

[71] James W. Pennebaker and Cindy K. Chung. 2011. Expressive Writing: Connections to Physical and Mental Health. Oxford University Press. DOI:https://doi.org/10. 1093/oxfordhb/9780195342819.013.0018

[72] Alison M. Radcliffe, Mark A. Lumley, Jessica Kendall, Jennifer K. Stevenson, and Joyce Beltran. 2010. Written Emotional Disclosure: Testing Whether Social Disclosure Matters. 7 Soc Clin Psychol 26, 3 (May 2010), 362-384. DOI:https: //doi.org/10.1521/jscp.2007.26.3.362

[73] Stephen A. Rains. 2014. The Implications of Stigma and Anonymity for SelfDisclosure in Health Blogs. Health Communication 29, 1 (January 2014), 23-31. DOI:https://doi.org/10.1080/10410236.2012.714861

[74] J. M. Richards, W. E. Beal, J. D. Seagal, and J. W. Pennebaker. 2000. Effects of disclosure of traumatic events on illness behavior among psychiatric prison inmates. F Abnorm Psychol 109, 1 (February 2000), 156-160. DOI:https://doi.org/ 10.1037//0021-843x.109.1.156

[75] Bernard Rimé. 2009. Emotion Elicits the Social Sharing of Emotion: Theory and Empirical Review. Emotion Review 1, 1 (January 2009), 60-85. DOI:https: //doi.org/10.1177/1754073908097189

[76] Bernard Rimé, Catrin Finkenauer, Olivier Luminet, Emmanuelle Zech, and Pierre Philippot. 1998. Social Sharing of Emotion: New Evidence and New Questions. European Review of Social Psychology 9, 1 (January 1998), 145-189. DOI:https: //doi.org/10.1080/14792779843000072

[77] Bernard Rimé, Batja Mesquita, Stefano Boca, and Pierre Philippot. 1991. Beyond the emotional event: Six studies on the social sharing of emotion. Cognition and Emotion 5, (January 1991), 435-465. DOI:https://doi.org/10.1080/ 02699939108411052

[78] Ayse Pinar Saygin and Ilyas Cicekli. 2002. Pragmatics in human-computer conversations. Fournal of Pragmatics 34, 3 (March 2002), 227-258. DOI:https: //doi.org/10.1016/S0378-2166(02)80001-7

[79] Stanley Schachter. 1959. The psychology of affiliation: Experimental studies of the sources of gregariousness. Stanford Univer. Press, Palo Alto, CA, US.

[80] Ulrike Schmidt, Gillian Bone, Saskia Hems, Joey Lessem, and Janet Treasure. 2002. Structured therapeutic writing tasks as an adjunct to treatment in eating disorders. European Eating Disorders Review 10, 5 (2002), 299-315. DOI:https: //doi.org/10.1002/erv.465

[81] Daniel Schulman, Timothy W. Bickmore, and Candace L. Sidner. 2011. An Intelligent Conversational Agent for Promoting Long-Term Health Behavior Change Using Motivational Interviewing. AAAI Spring Symposium: AI and Health Communication. Retrieved September 14, 2018 from /paper/An-Intelligent-Conversational-Agent-for-Promoting-SchulmanBickmore/cb125d3aa69f8eb9b242321617a5ed96365d9118

[82] Mari Sengoku, Hiroaki Murata, Takanobu Kawahara, Kaori Imamura, and Kazuyuki Nakagome. 2010. Does daily Naikan therapy maintain the efficacy of intensive Naikan therapy against depression? Psychiatry and Clinical Neurosciences 64, 1 (2010), 44-51. DOI:https://doi.org/10.1111/j.1440-1819.2009.02049.x

[83] Joshua Smyth and Rebecca Helm. 2003. Focused expressive writing as self-help for stress and trauma. Fournal of Clinical Psychology 59, 2 (2003), 227-235. DOI:https: //doi.org/10.1002/jclp.10144

[84] Joshua M. Smyth, Deborah Nazarian, and Danielle Arigo. 2008. Expressive Writing in the Clinical Context. In Emotion Regulation: Conceptual and Clinical Issues, Ad J.J.M. Vingerhoets, Ivan Nyklíček and Johan Denollet (eds.). Springer US, Boston, MA, 215-233. DOI:https://doi.org/10.1007/978-0-387-29986-0_14

[85] Joshua Smyth, Nicole True, and Joy Souto. 2001. Effects of Writing About Traumatic Experiences: The Necessity for Narrative Structuring. Fournal of Social and Clinical Psychology 20, 2 (June 2001), 161-172. DOI:https://doi.org/10.1521/jscp. 20.2.161.22266

[86] Peter Suedfeld and James W. Pennebaker. 1997. Health Outcomes and Cognitive Aspects of Recalled Negative Life Events. Psychosomatic Medicine 59, 2 (April 1997), 172-177.

[87] Yla R. Tausczik and James W. Pennebaker. 2010. The Psychological Meaning of Words: LIWC and Computerized Text Analysis Methods. fournal of Language and Social Psychology 29, 1 (March 2010), 24-54. DOI:https://doi.org/10.1177/ 0261927X09351676

[88] Dina Utami, Timothy W. Bickmore, and Louis J. Kruger. 2017. A robotic couples counselor for promoting positive communication. In 2017 26th IEEE International 
Symposium on Robot and Human Interactive Communication (RO-MAN), IEEE, Lisbon, 248-255. DOI:https://doi.org/10.1109/ROMAN.2017.8172310

[89] Liisa Voutilainen, Anssi Peräkylä, and Johanna Ruusuvuori. 2010. Recognition and Interpretation: Responding to Emotional Experience in Psychotherapy. Research on Language and Social Interaction 43, 1 (February 2010), 85-107. DOI:https: //doi.org/10.1080/08351810903474799

[90] Joseph Weizenbaum. 1966. ELIZA-A computer program for the study of nat ural language communication between man and machine. Commun. ACM 9, 1 (January 1966), 36-45. DOI:https://doi.org/10.1145/365153.365168

[91] Carla Willig and Wendy Stainton Rogers. 2017. The SAGE Handbook of Qualitative Research in Psychology. SAGE.

[92] Diyi Yang, Zheng Yao, Joseph Seering, and Robert Kraut. 2019. The Channel Matters: Self-disclosure, Reciprocity and Social Support in Online Cancer Support Groups. In Proceedings of the 2019 CHI Conference on Human Factors in Computing
Systems (CHI '19), Association for Computing Machinery, New York, NY, USA, 1-15. DOI:https://doi.org/10.1145/3290605.3300261

[93] Emmanuelle Zech and Bernard Rimé. 2005. Is talking about an emotional experience helpful? effects on emotional recovery and perceived benefits. Clinical Psychology \& Psychotherapy 12, 4 (2005), 270-287. DOI:https://doi.org/10.1002/ cpp. 460

[94] Chunlan Zhou, Yanni Wu, Shengli An, and Xiaojin Li. 2015. Effect of Expressive Writing Intervention on Health Outcomes in Breast Cancer Patients: A Systematic Review and Meta-Analysis of Randomized Controlled Trials. PLoS ONE 10, 7 (2015), e0131802. DOI:https://doi.org/10.1371/journal.pone.0131802

[95] WoeBot, The Chatbot Therapist, Will See You Now | WIRED. Retrieved February 6, 2019 from https://www.wired.com/2017/06/facebook-messenger-woebotchatbot-therapist/ 